Journal of Economics and Behavioral Studies

Vol. 4, No. 9, pp. 497-504, Sep 2012 (ISSN: 2220-6140)

\title{
Threshold Effects and Asymmetric Price Adjustments within the Ghanaian Maize Market
}

\author{
Henry de-Graft Acquah \\ University of Cape Coast, Ghana \\ henrydegraftacquah@yahoo.com
}

\begin{abstract}
This study investigated co integration and asymmetric adjustments in the end equilibrium between Ghanaian retail and wholesale maize markets using the Enders and Siklos technique. Two competing models, namely Consistent Threshold Autoregressive (C-TAR) and Consistent Momentum Threshold Autoregressive (C-MTAR) models were estimated. Following the application of a standard model selection technique, CMTAR model is selected as most appropriate. The results of the C-MTAR model confirm that the retail and wholesale prices of maize in Ghana are co integrated with threshold adjustment. Furthermore, it suggests that the process is asymmetric when the retail and wholesale prices of Ghanaian maize adjust to achieve the longterm equilibrium. Additionally, the adjustment is relatively faster when the price differential is increasing than when it is decreasing.
\end{abstract}

Keywords: Asymmetric price transmission; Threshold adjustment; Co integration, AIC, BIC

\section{Introduction}

The agricultural market is characterized by movements in the commodity prices that typically depend on several of factors, both exogenous and endogenous. These movements may be upwards or downwards in response to changes in the predictors. However, the magnitude of positive and negative responses may differ for similar positive and negative variations in the predictors. In such a case, we can say that the variables display asymmetric adjustment in the price transmission process. Standard linear co integration models have been employed in measuring asymmetric adjustments. However, they do not capture the full extent of price dynamics when there is asymmetric adjustment to the long run equilibrium. This is because they assume symmetric adjustment. Under this condition, the unit roots and co integration tests in the presence of asymmetric adjustment have low power. In order to address these problems, Enders and Siklos (2001) introduce the threshold co integration analysis, which extends the Engle and Granger's procedure to encompass possible asymmetric adjustment to equilibrium. However, previous studies analyzing price asymmetry in Ghanaian maize markets have not focused on testing asymmetric adjustment in the long run relationship between the retail and wholesale prices using the recently developed Enders and Siklos procedure. Empirically, no studies have been devoted to apply the methodology to examine whether the adjustment is asymmetric within the Ghanaian vertical maize markets. Additionally, the nature of vertical price transmission in the Ghanaian maize market is an issue that has not received adequate attention. This research fills the gap by employing the recently developed Enders and Siklos (2001) threshold co integration methodology to empirically test the existence of asymmetries in the long run relationship between the retail and wholesale maize prices. Subsequently, the threshold autoregressive (TAR) and momentum threshold autoregressive (MTAR) models are estimated to address the problem of asymmetry within the Ghanaian retail and wholesale maize markets. First, this study test for evidence of co integration between the retail and wholesale prices. Second, this study test for evidence of asymmetric adjustment in the long run equilibrium.

\section{Literature Review}

Numerous studies have focused on investigating price transmission using the Houck's approaches, which segment prices in increasing and decreasing phases to enable it test for asymmetry. However, the Houck's method doe not account for the long run relationship between the price series. Subsequently, Engle and Granger (1987) introduce the Error Correction Modeling, which allows the test for asymmetry to take into consideration the long run relationship between the price series. However, their methodology considers 
symmetric adjustments to the long run equilibrium relationship. Under these conditions, the power of the test for asymmetry is low as noted in Cook et al 1999. Subsequently, efforts to address this problem of low power of the test for asymmetry led to the development of the threshold models. Tong (1983), draws on the threshold approach and consider an intuitively appealing type of Error Correction Model in which deviation from the long-run equilibrium between prices $P_{A}$ and $P_{B}$ will lead to a price response if they exceed a specific threshold level. Several studies measuring asymmetric price transmission using the threshold approach estimates variants of the following simplified equation.

Standard Threshold Co integrated Model

$\Delta P_{A, t}=\beta_{\mathrm{o}}+\beta_{1} \Delta P_{B, t}+\beta_{2}{ }^{+} E C T^{+}{ }_{t-1}+\beta_{2}^{-} E C T^{-}{ }_{t-1}+\varepsilon_{t}$

Given a threshold $(\gamma)$, where: $E C T^{+}{ }_{t-1}>\gamma$ and $E C T^{-}{ }_{t-1} \leq \gamma$

The Error Correction Term (ECT) is segmented into $E C T^{+}$and $E C T^{-}$according to whether it is greater or less than a defined threshold value respectively. Detailed discussion on the threshold modeling is provided in numerous studies including (Enders, 2004; Balke and Fomby, 1997 and Tsay, 1998). Enders and Siklos (2001) presented a model that allows for nonlinear adjustment to equilibrium by introducing the concept of threshold co integration. The relationship between symmetry and threshold is systematically developed in von Cramon-Taubadel and Meyer (2004). Following the development of the threshold model, a number of applications have estimated asymmetric adjustments using threshold error correction models. Abdulai (2002) draws on Enders and Granger (1998) to test for asymmetric price transmission in a methodology in which the threshold parameter $(\gamma)$ is set to zero. He uses both the threshold autoregressive model (TAR) and momentum threshold autoregressive model (MTAR) to estimate asymmetric price transmission in the Swiss pork markets and finds that price transmission between producer and retail level is asymmetric. Abdulai (2000) also analyzes spatial price transmission and asymmetry in the Ghanaian maize markets finds evidence of price asymmetry on the basis of the TAR and MTAR models. Alternatively, Goodwin and Harper (2000) and Goodwin and Piggott (2001) use a grid search to find optimal thresholds in price transmission analysis. Hansen and Seo (2002) develop a test for the significance of a single threshold in an error correction model where the ECT is segmented not according to whether it is greater or less than zero but rather according to whether it is greater or less than a threshold value that might differ from zero. In an empirical application, Aguero (2004) uses a threshold error correction model to estimate price adjustments under risk in the Peruvian agricultural markets.

\section{Methodology}

The methodology describes the time series data and the econometric procedures employed in the study. An econometric technique such as Granger Causality is useful in resolving the issue of causal direction between the price series. Kwiatkowski, Phillips, Schmidt and Shin (KPSS) test is used to test for stationary. Enders and Siklos Threshold co integration technique is employed to test for evidence of co integration and asymmetry in the long run equilibrium between the prices.

Data: This study uses weekly retail and wholesale prices for maize from January 1994 to December 2003 from Kumasi in the Ashanti Region of Ghana. The weekly data for all prices are Ghana cedi per 100kg and given the high level of inflation in the period covered, prices are deflated using consumer price index (CPI) deflator. The data was obtained from the Ministry of Food and Agriculture in Ghana.

Granger Causality: The ordinary least square normally identifies the correlation between variables but does not help to determine the direction of the relationship. If changes in X precede changes in $Y$, we can rule out $Y$ causing X. Based on this, we can estimate a regression of the following form:

$$
Y_{t}=\beta_{o}+\sum \beta_{j} Y_{t-j}+\sum c_{j} X_{t-j}+u_{t}
$$

If past values of $X$ help determine current values of $Y$, we say $X$ Granger causes $Y$. The test of $H_{0}: c_{i}=0$ can be carried out with an F test. The number of lags may be chosen using the Akaike Information Criteria (AIC) and 
Bayesian Information Criteria (BIC) or Adjusted $\mathrm{R}^{2}$. The AIC and BIC model selection methods were employed. The short run effect is given by $\sum c_{j}$ and the long run by $\sum c_{j} /\left(1-\sum \beta_{j}\right)$.

Test for Stationarity: The Kwiatkowski, Phillips, Schmidt and Shin (KPSS) test for stationarity proceeds by testing for the presence of a random walk component $r_{t}$ in the regression

$\mathrm{Y}_{\mathrm{t}}=\mathrm{d}_{\mathrm{t}}+\mathrm{r}_{\mathrm{t}}+\varepsilon_{\mathrm{t}}$

Where $d_{t}$ denotes a deterministic component and $\varepsilon_{t}$ is stationary, more precisely I $(0)$ error process. The KPSS test takes the null hypothesis as a stationary process and the unit root as the alternative hypothesis.

Threshold Adjustments: The long run equilibrium relationship between any two non-stationary time series can be estimated as a standard regression model:

$y_{t}=\beta_{0}+\beta_{1} x_{1}+u_{t}(1)$

Where $y_{t}$ and $x_{1}$ are non-stationary variables, $\beta_{1}$ is a parameter to be estimated and $u_{t}$ is the disturbance term.

Subsequently, the ordinary least squares technique is employed to estimate $\rho$ in the following relationship:

$\Delta u=\rho u_{t-1}+\varepsilon_{t}$

Where $\varepsilon_{t}$ is a white noise disturbance. The rejection of the hypothesis of no co integration (i.e. accepting the alternative hypothesis of $-2<\rho<0$ ) suggest that the residuals in equation 2 are stationary with mean zero. If convergence is assured, that is $-2<\rho<0$, then equation 1 becomes an attractor such that $u_{t}$ can be written as an error correction model.

Alternatively, equation 2 can be written as:

$\Delta u_{t}=I_{t} \rho_{1} u_{t-1}+\left(1-I_{t}\right) \rho_{2} u_{t-1}+\varepsilon_{t}$

Where $I_{t}$ is the Heaviside indicator function such that

$I_{t}=\left\{\begin{array}{l}1 \text { if } u_{t-1} \geq 0 \\ 0 \text { if } u_{t-1}<0\end{array}\right\}$

The model specification illustrated in equation 3 is referred to as the threshold autoregressive (TAR) model. That is equation 3 and 4 . It allows different coefficients for positive and negative deviations. A sufficient condition for the stationarity of $u_{t}$ is $-2<\left(\rho_{1}, \rho_{2}\right)<0$ if $\rho_{1}=\rho_{2}$, then the adjustment is symmetric, which is a special case of equation 3 and 4 . The lagged values of $\Delta u_{t}$ can also be included in equation 3 . An alternative adjustment specification is to allow the decay to depend on the previous period change in $u_{t-1}$ which is referred to as the momentum threshold autoregressive (MTAR) model. Thus, equation 4 can be replaced with equation 5 .

$I_{t}=\left\{\begin{array}{l}1 \text { if } \Delta u_{t-1} \geq 0 \\ 0 \text { if } \Delta u_{t-1}<0\end{array}\right\}$

In relationship 4, the Heaviside indicator depends on the sign of the level of $u_{t-1}$. Thus, if $u_{t-1}$ is above its equilibrium value, the adjustment is $\rho_{1} u_{t-1}$ and when $u_{t-1}$ is below its long run equilibrium value, the adjustment is $\rho_{2} u_{t-1}$. In equation 5 , the adjustment is now allowed to depend on the sign of the change of $u_{t-1}$ in the previous period. The TAR model is developed to capture asymmetrically deep movements in the deviations from the long run equilibrium, while the MTAR model is useful to capture the possibility of asymmetrically "steep" movements in the deviations. Negative deepness (i.e. $\left|\rho_{1}\right|<\left|\rho_{2}\right|$ of the residuals means that increases tend to persist but decreases tend to revert quickly towards the equilibrium (Enders and Granger, 1998).

Subsequently, a number of statistical tests can be performed on the estimated coefficients in order to ascertain whether the variables are co integrated and in such a case, if the adjustment is symmetric or not. The relevant tests are $H_{0}: \rho_{1}=0$ and $H_{0}: \rho_{2}=0$, for which we obtain the sample values of the $t$ statistics; and $H_{0}: \rho_{1}=\rho_{2}=0$, for which we obtain the sample values of the $\mathrm{F}$ statistics. These values are compared with the appropriate critical values to determine whether the null hypothesis of a unit root can be rejected. If the alternative hypothesis is accepted, it is possible to test for asymmetric adjustment, since $\rho_{1}$ and $\rho_{2}$ converge to a multivariate normal distribution. The restriction that the adjustment is symmetric i.e. $H_{0}: \rho_{1}=\rho_{2}$ can be 
tested using the usual F-statistics. Chan (1993) introduced a method of obtaining a consistent estimate of the threshold value. Under the Chan's procedure, the value of the threshold under which the adjustment occurs is derived by re ordering the residuals in ascending size. A number of values of the reordered series are then considered in turn as alternative threshold values $(\boldsymbol{\tau})$. The consistent threshold value is selected as the value of the residual minimizing the sum of square residuals. In order to ensure that sufficient degrees of freedom, are present in both regimes, $15 \%$ of the highest and lowest values of the re ordered series are excluded from the grid search identifying $\tau$. The middle $70 \%$ values of the sorted threshold variables are used as potential threshold values.

\section{Results and Discussion}

In estimating the asymmetric price transmission equation, it is imperative to test for the direction of causality to ensure that the asymmetric price transmission model is not miss-specified. In order to resolve the issue of causal direction, the Granger causality test is carried out to determine the direction of causality between the retail and wholesale maize prices as illustrated in Table 1.

Table 1: Granger causality test

\begin{tabular}{lllll}
\hline Market & Effect & Hypothesized Cause & F Statistic & p-value \\
\hline Kumasi & Retail Price & Wholesale Price & 3.659 & 0.03 \\
& Wholesale Price & Retail Price & 0.462 & 0.63 \\
\hline
\end{tabular}

Source: Author's calculation

The hypothesis that wholesale prices Granger cause retail prices and vice versa must be tested. This hypothesis rests on a regression of retail price as a function of lagged retail and wholesale prices as well as a regression of wholesale price as a function of lagged wholesale and retail prices. If wholesale prices Granger cause retail prices, then in the case where retail price is the dependent variable, the F-test corresponding to all coefficients associated with lagged wholesale prices should be statistically significant. If retail prices fail to Granger cause wholesale prices, then, in the case where wholesale price is the dependent variable, the F-test corresponding to all coefficients associated with lagged retail prices should not be statistically significant. From the results of Granger causality test in Table 1, it can be concluded that the wholesale prices Granger causes the retail prices. Co integration between the respective wholesale and retail price series is considered. The Kwiatkowski, Phillips, Schmidt and Shin (KPSS) test for stationarity (Kwiatkowski, et al., 1992) was used to check on the stationarity of the retail and wholesale price series. The application of the Kwiatkowski et al. (1992) test confirmed that the time series of the variables under consideration are non-stationary and integrated of the order one as illustrated in Table 2.

Table 2: KPSS unit root test

\begin{tabular}{clllll}
\hline & Test statistics & \multicolumn{3}{c}{ Critical values } & \\
& & $\mathbf{1 0}$ & $\mathbf{5}$ & $\mathbf{2 . 5}$ & $\mathbf{1}$ \\
\hline Wholesale ( Levels) & 0.2755 & 0.119 & 0.146 & 0.176 & 0.216 \\
(First Difference) & 0.017 & 0.119 & 0.146 & 0.176 & 0.216 \\
Retail (levels) & 0.3839 & 0.119 & 0.146 & 0.176 & 0.216 \\
(First Difference) & 0.0151 & 0.119 & 0.146 & 0.176 & 0.216 \\
\hline
\end{tabular}

Source: Author's calculation

The analysis is implemented using the Threshold Autoregressive models. The Consistent Threshold Autoregressive Model (C-TAR) and Consistent Momentum Threshold Autoregressive Model (C-MTAR) are estimated and the results are displayed in Table 3. In selecting an appropriate lag to address possible serial correction in the residual series, a maximum lag of 12 is specified and tried at the beginning. Diagnostic analyses on the residuals through AIC and BIC all reveal that a lag of 2 is sufficient. In estimating the threshold values for Consistent TAR, the method by Chan (1993) is followed. The lowest sum of squared errors for the 
consistent TAR model is 1191.69 at the threshold value of -2.554 . Whilst the lowest sum of squared errors for the consistent MTAR model is 1181.563 at the threshold value of 0 .

Table 3: Estimates of the speed of adjustments parameters of the Threshold Models

\begin{tabular}{llll}
\hline & $\begin{array}{l}\text { Consistent } \\
\text { Autoregressive Model(CTAR) }\end{array}$ & $\begin{array}{l}\text { Threshold } \\
\text { Consistent } \\
\text { Autoregressive Model (MCTAR) }\end{array}$ & Threshold \\
\hline $\boldsymbol{\rho}_{\mathbf{1}}$ & $-0.11202(-4.567)^{1}$ & $-0.16068(-6.429)^{1}$ \\
$\boldsymbol{\rho}_{\mathbf{2}}$ & $-0.19787(-4.237)^{1}$ & $-0.03049(-0.709)^{1}$ \\
$\boldsymbol{\rho}_{\mathbf{1}} \boldsymbol{\rho}_{\mathbf{1}}=\mathbf{0}$ & $18.371(0.000)^{2}$ & $20.727(0.000)^{2}$ & \\
$\boldsymbol{\rho}_{\mathbf{1}}=\boldsymbol{\rho}_{\mathbf{1}}$ & $2.779(0.096)^{2}$ & $7.201(0.008)^{2}$ \\
$\gamma$ & -2.554 & 0 & \\
SSE & 1191.693 & 1181.563 \\
AIC & 1908.923 & 1904.509 \\
BIC & 1930.163 & 1925.749 & \\
\hline
\end{tabular}

Notes: ${ }^{1}$ Values in the parentheses are t values. ${ }^{2}$ Values in the parentheses are estimated probability values; outside parentheses are the $\mathrm{F}$ statistic values.

Source: Author's calculation

Although the competing nonlinear threshold co integration models finds evidence of threshold co integration and asymmetry as displayed in Table 3, the C-MTAR model has the lowest AIC statistic of 1904 and BIC statistic of 1925, and therefore, is deemed to provide a better model fit to the data than the C-TAR. Emphasizing the results from the Consistent MTAR model, the F-test for the null hypothesis of no co integration has a statistic of 20.727 and it is highly significant at the $1 \%$ level as indicated in Table 4. Thus, the retail and wholesale prices of maize in Ghana are co integrated with threshold adjustment. Furthermore, the F statistic for the null hypothesis of symmetric price transmission has a value of 7.201 and it is significant at the $10 \%$ level as indicated in Table 5. In effect, the adjustment process is asymmetric when the retail and wholesale prices of Ghanaian maize adjust to achieve the long-term equilibrium. The point estimate for the price adjustment is -0.16068 for positive shocks and -0.03049 for negative shocks. The point estimate of $\rho_{1}$ $(-0.16068)$ for the retail and wholesale prices indicates that approximately $16.1 \%$ of a positive deviation from the long-run equilibrium relation is eliminated within a week. On the other hand, the point estimate of $\rho_{2}(-0.03049)$ indicates that $3 \%$ of a negative deviation from the long-run equilibrium relation is eliminated within a week. This implies that $84 \%$ of the positive deviation and $97 \%$ of the negative deviation persist to the next period. In effect, the adjustment is almost 5.3 times faster for positive deviations from equilibrium than for negative deviations. Therefore, there is substantially faster convergence for positive (above threshold) deviations from long-term equilibrium than negative (below threshold) deviations.

Table 4: Hypothesis - No co integration between the two variables using C-MTAR

\begin{tabular}{lllllll}
\hline & Res. DF & RSS & DF & Sum of sq & F & Pr(>F) \\
\hline Restricted model & 515 & 1277.0 & & & & \\
& & & & & & \\
Unrestricted model & 513 & 1181.6 & 2 & 95.479 & 20.727 & $2.206 \mathrm{e}-09^{* * *}$ \\
\hline Significance codes: $0^{(* * *)}, 0.001^{(* *)}, 0.01^{(*)}, 0.05^{\prime \prime}, 0.1^{\prime \prime} 1$ & &
\end{tabular}

Significance codes: $0^{(* * *)}, 0.001^{(* * \prime}, 0.01^{\text {(*), }}, 0.05^{\prime \prime}, 0.1^{\prime \prime} 1$

Source: Author's calculation

Table 5: Hypothesis- Symmetric adjustment in the long run equilibrium using C-MTAR

\begin{tabular}{lllllll}
\hline & Res. DF & RSS & DF & Sum of sq & F & Pr(>F) \\
\hline Restricted model & 514 & 1198.2 & & & &
\end{tabular}

\begin{tabular}{cccrrrr} 
Unrestricted model & 513 & 1181.6 & 1 & 16.586 & 7.201 & $0.007521^{* *}$ \\
\hline Significance codes: $0^{(* * *)}, 0.001^{(* *)}, 0.01^{* *}, 0.05^{\prime \prime,}, 0.1^{\prime \prime} 1$ & &
\end{tabular}

Source: Author's calculation 
Previous studies such as Abudulai (2000) analyzed the spatial Ghanaian maize markets found evidence of asymmetry on the basis of the TAR and MTAR models. The result from the current study of the Ghanaian retail and wholesale maize prices indicates that the markets are asymmetric. In effect, it is not only the spatial maize markets that suffer from price asymmetry but also the vertical maize markets also behave in an asymmetric manner.

\section{Conclusion}

This study investigated co integration and asymmetric adjustments in the end equilibrium between Ghanaian retail and wholesale maize markets using threshold co integration technique. The results of the KPSS test for the order of integration of the price series indicated that the retail and wholesale prices are non-stationary and integrated of the order one. The threshold co integration analysis indicated that retail and wholesale prices of maize in Ghana are co integrated with threshold adjustment. Additionally, the price transmission process is asymmetric when the retail and wholesale prices of Ghanaian maize adjust to achieve the longterm equilibrium. On the basis of the C-MTAR, this study finds that the negative shocks to the marketing margin tend to persist, but relatively positive shocks revert quickly towards equilibrium. In effect, this suggests the existence of negative asymmetry. In other for public policy to address the issue of the existence of asymmetry in the Ghanaian vertical maize market, it is necessary for future research to investigate the reasons underlying this asymmetric price transmission.

\section{References}

Abdulai, A. (2000). Spatial price transmission and asymmetry in the Ghanaian maize market. Journal of Development Economics, 63, 327-349.

Abdulai, A. (2002). Using Threshold Co integration to estimate asymmetric Price Transmission in the Swiss Pork Market. Applied Economics, 34, 679-687.

Aguero, J. (2004). Asymmetric Price Adjustments and Behavior under Risk: Evidence from Peruvian Agricultural Markets. Selected Paper prepared for presentation at the American Agricultural Economics Association Annual Meeting, Denver, Colorado, and July 1-4, 2004.

Balke, N. S. \& Fomby, T. (1997).Threshold Co integration. International Economic Review, 38, 627-645.

Chan, K. S. (1993). Consistency and limiting distribution of the least squares estimator of a threshold autoregressive model. The Annals of Statistics, 21, 520-533.

Cramon-Taubadel, S. V. \& Meyer, J. (2000). Asymmetric Price Transmission: Fact or Artifact? University Gottingen, Institute for Agricultural Economics, Working Paper.

Dickey, D. \& Fuller, W. A. (1979). Distribution of the estimators for autoregressive time series with a unit root. Journal of the American Statistical Association, 74, 427-431.

Enders, W. \& Granger, C. W. J. (1998).Unit-root tests and asymmetric adjustment with an example using the term structure of interest rates. Journal of Business \& Economic Statistics, 16, 304-311.

Enders, W. \& Siklos, P. L. (2001).Co integration and threshold adjustment. Journal of Business and Economic Statistics, 19, 166-176.

Enders, W. (2004). Applied Econometric Time Series (2nded.) New Jersey: John Wiley and Sons Ltd.

Engle, R. F. \& Granger, C. W. J. (1987). Co integration and error correction: representation, estimation, and testing. Econometrica, 55, 251-276.

Goodwin, B. K. \& Harper, D. C. (2000). Price Transmission, Threshold Behavior and asymmetric Adjustment in the U.S. Pork Sector. Journal of Agricultural and Applied Economics, 32, 543-553.

Goodwin, B. K. \& Piggott, N. E. (2001). Spatial Market Integration in the Presence of Threshold Effects. American Journal of Agricultural Economics, 83(2), 302- 317.

Hansen, B. E. \& Seo, B. (2002).Testing for Two-Regime Threshold Co integration in Vector Error Correction Models. Journal of Econometrics, 110, 293-318.

Kwaitkowski, D., Phillips, P. C. B., Schmidt, P. \& Shin, Y. (1992). Testing the null hypothesis of stationary against the alternative of a unit root. Journal of Econometrics, 54, 159-178.

Tong, H. (1983).Threshold Models in Non-Linear Time Series Analysis. New York, Springer Verlag.

Tsay, R. S. (1989). Testing and Modeling Threshold Autoregressive Processes. Journal of the American Statistical Association, 84, 231-240. 


\section{Appendix}

Table 6: Hypothesis 1: No co integration between the two variables using CTAR

\begin{tabular}{lllllll}
\hline & Res. DF & RSS & DF & Sum of sq & F & Pr(>F) \\
\hline Restricted model & 515 & 1277.0 & & & & \\
& & & & & & \\
Unrestricted model & 513 & 1191.7 & 2 & 85.349 & 18.370 & $1.970 \mathrm{e}-08^{* * *}$ \\
\hline Significance codes: $0^{(* * *)}, 0.001^{(* *)}, 0.01^{(*)}, 0.05{ }^{\prime \prime}, 0.1^{\prime \prime} 1$ & & &
\end{tabular}
Source: Author's calculation

Table 7: Hypothesis 2: Symmetric adjustment in the long run equilibrium using CTAR

\begin{tabular}{lllllll}
\hline & Res. DF & RSS & DF & Sum of sq & F & Pr(>F) \\
\hline Restricted model & 514 & 1198.2 & & & & \\
& & & & & & \\
Unrestricted model & 513 & 1191.7 & 1 & 6.4553 & 2.7789 & 0.09613. \\
\hline
\end{tabular}

Significance codes: $0^{(* * *)}, 0.001^{\text {(**) }}, 0.01^{\text {(*), }} 0.05^{\prime \prime,}, 0.1^{\prime \prime} 1$

Source: Author's calculation

Figure 1: Best Threshold Value for C-TAR Model

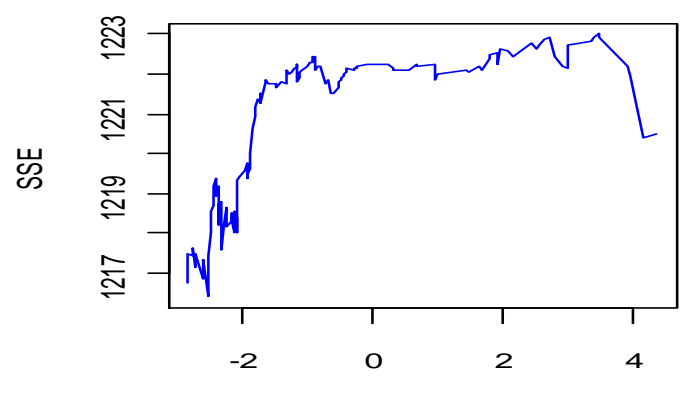

threshold value for tar

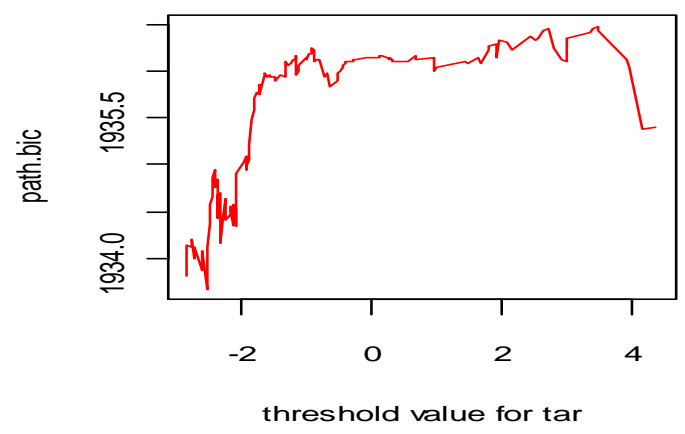

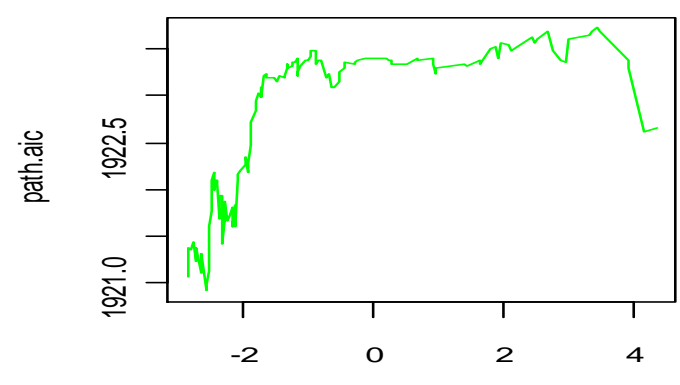

threshold value for tar 
Figure 2: Best Threshold Value for the C-MTAR
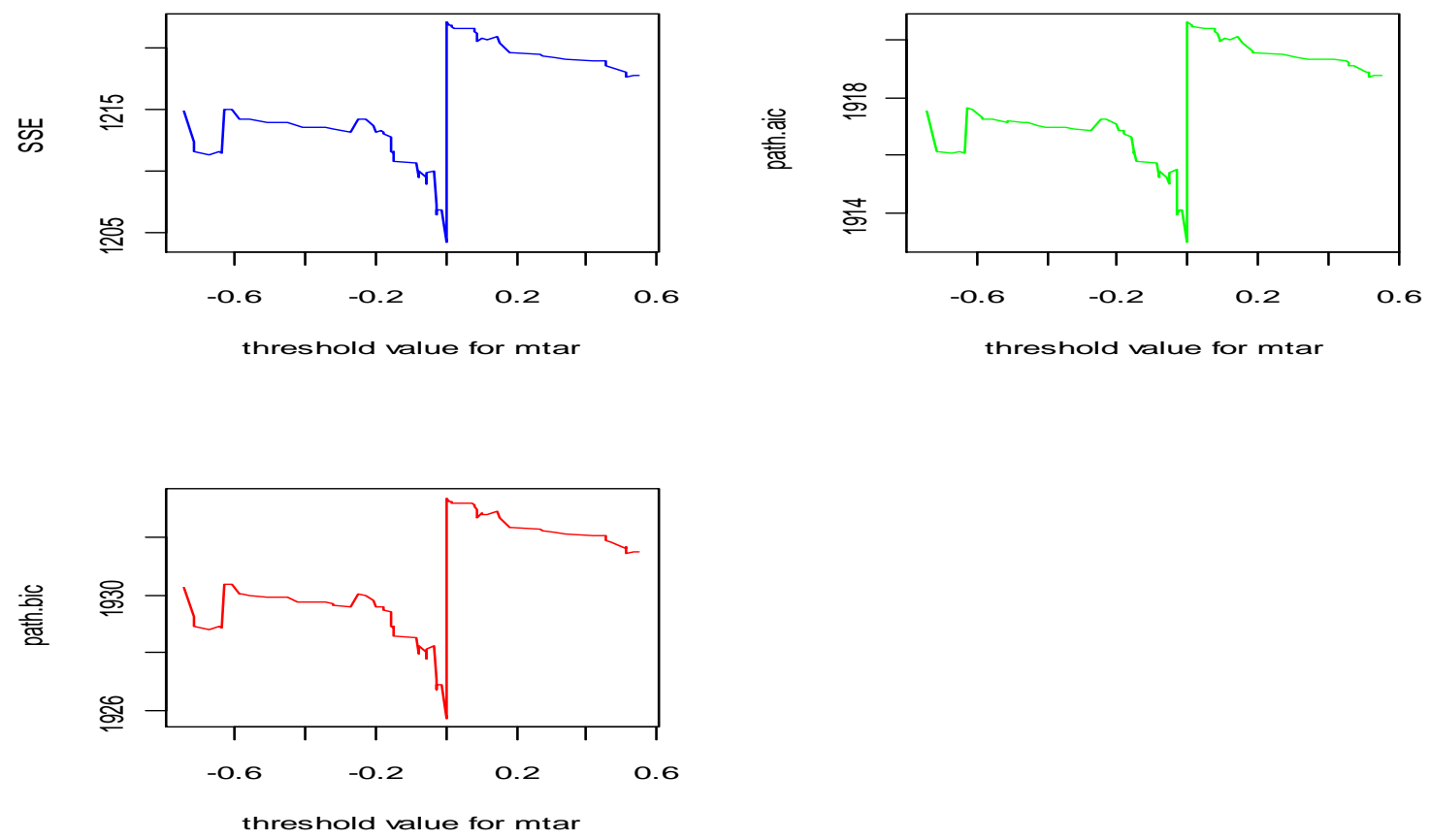